\title{
Editorial
}

Ophthalmic

Ophthalmic Res 2015;54:109-111

Received: July 18, 2015

Research

DOI: 10.1159/000438794

Accepted: July 19, 2015

Published online: August 21, 2015

\section{Diabetic Retinopathy: Need for More Research to Understand the Relative Role of Neuropathy and Microvascular Disease}

Diabetic retinopathy (DR) is a frequent complication of diabetes and through its sight-threatening complications, i.e. macular edema and proliferative retinopathy, may lead to blindness. Indeed, DR is the leading cause of vision loss in working age adults (International Diabetes Foundation, 2013).

Recent advances in therapy, particularly intravitreal administration of anti-angiogenic agents, have opened new perspectives of vision recovery. However, the availability of treatment only for the late stages of the disease and its rate of success make it urgent to understand the early alterations of DR and their progression in order to develop timely treatments before vision loss.

DR is said to be present when microaneurysms and small hemorrhages appear on ophthalmoscopic examination. On histopathological examination, the vascular changes are initiated in the small vessels in the form of endothelial proliferation, pericyte damage and microaneurysms [1]. These initial lesions are focal and located at the posterior pole of the retina. At first the endothelial proliferation and microaneurysms appear to be confined to the venous side of the retinal circulation, whereas at this stage endothelial degeneration appears to be limited to capillaries on the arterial side. The pericyte damage stands out in retinal digests, but their association with microvascular changes is irregular.
With progression of disease the capillaries of the arterial side of the retinal circulation show increased vasoregression, with cell loss and closure. Simultaneously, the number of microaneurysms increases, and the areas of capillary closure enlarge. As they enlarge, they are seen to be crossed by the remaining enlarged capillaries, which appear to act as arteriovenous shunts, receiving the blood directed from the surrounding closed capillary net. These microvascular lesions, microaneurysms, capillary closure, basement membrane thickening and pericytic damage are different from other vascular retinopathies only in their intensity and distribution [2].

Hyperglycemia appears to be sufficient to initiate the development of DR as revealed by the development of retinopathy in animals experimentally made hyperglycemic [3].

However, the observation that not all patients with poor metabolic control develop advanced stages of DR suggests that other factors, such as genetic predispositions, are likely to determine individual susceptibility to the disease [4]. Even for type 1 diabetes, despite the fact that glycemia is the major risk factor for DR, its overall contribution is only $11 \%$, i.e. $89 \%$ of the risk has to be explained by other factors [5].

The retina consists of three major types of cells - neurons, glial cells and blood vessels - and most, if not all, of 
these cell types are affected to some degree by diabetes. The inner blood-retina barrier, which is a specific and a unique structure in the retina, is affected early in diabetes. It is formed by the endothelial cells, the pericytes and the glial cells immediately surrounding the retinal vessels [6].

The earliest alterations that may be detected clinically in the retina in diabetes are the breakdown of the bloodretina barrier and alterations in the neurosensory retinal function. Both these alterations can be detected before ophthalmoscopic signs of DR are visible, in preclinical retinopathy $[7,8]$.

It has been proposed by Antonetti et al. [9] that dysfunction of the inner retina may affect neurons and glial cells and induce changes in the neurovascular unit and blood-retina barrier before obvious signs of vascular lesions. Diabetes increases the cell death of neurons in the inner retina including retinal ganglion cells and both dopaminergic and cholinergic amacrine cells, and cell death has been identified in both animal models and in human samples. It is likely that there is also accelerated cell death of bipolar cells and some photoreceptors. Several recent clinical studies have used imaging techniques to demonstrate thinning of the retinal nerve fiber layer in diabetes, often in patients with little or no evidence of vascular retinopathy.

Finally a large body of evidence supports the role of inflammation in the pathogenesis of DR [10]. It has been associated with the universal endothelial dysfunction occurring in diabetes as a repair process. An emerging issue in DR research is the focus on the mechanistic link between the activation of subclinical inflammation and neurodegeneration.

DR has been generally accepted to be a microvascular complication of diabetes limiting the diagnostic and therapeutic focus to the vascular system. However, there is now evidence that DR involves the neuronal as well as the vascular compartments $[8,9]$.

The neurosensory retina has been shown to be altered in diabetes even before detection of microvascular changes on ophthalmoscopy [8]. Together with reduced corneal nerve sensation and impaired autonomic innervation of the pupil, altered function of the retinal sensory nerve indicates that diabetes causes denervation of multiple sensory inputs to the eye. These are strong arguments for a diabetic retinal peripheral sensory neuropathy.

Independently or subsequently to this retinal neuropathy, there are microvascular alterations characterized by alteration of the blood-retina barrier and vascular leakage very early in the disease process, leading in certain patients to macular edema and later in the disease process to neovascularization with tufts of new abnormally permeable vessels in the proliferative stage of the disease.

These neuronal and microvascular changes appear also to occur to a different degree in different patients. Not all patients show a detectable alteration of the bloodretina barrier in the early stages of the disease, and not all patients present electrophysiological changes in the same stage of the disease.

It should also be kept in mind that an altered bloodretina barrier implies also an inflammatory response and may serve as a link between the neurodegenerative and microvascular changes [11].

The link between neurodegeneration and microvascular disease remains however open to question. Recent findings suggest that these two components of retinal disease due to diabetes may run independently [12].

There is a neuropathy, apparently associated with duration of disease, involving primarily the ganglion cells of the retina and probably other neuronal components that occurs quite early in the diabetic retinal disease process which is detected by multifocal electroretinography delays in implicit times with associated thinning of the inner retinal layers.

In a few patients, however, microvascular damage occurs with alteration of the blood-retina barrier, manifested by thickening of the inner nuclear layer and neighboring retinal layers, apparently resulting from leakage and increase in the retinal extracellular space around the deep retinal capillary net as shown in the articles by the EVICR. net published in this issue.

Preliminary results support the concept that the occurrence and progression of microvascular disease are related to genetic factors [13] and may be independent of the diabetic retinal neuropathy. Heritability has, indeed, been estimated to be as high as $27 \%$ for DR and $52 \%$ for proliferative DR [14].

It is also possible that the occurrence of diabetic retinal neuropathy induces an autoregulatory response by the retinal vessels in the neighboring areas of the retina, which if maintained may lead to prolonged vasodilatation, leakage (alteration of the blood-retina barrier) and the development of the microvasculopathy and the clinical picture of DR as identified in daily clinical practice. The advent of optical coherence tomography-microangiography appears to be particularly promising to clarify this question.

José G. Cunha-Vaz, Coimbra 


\section{References}

1 Ashton N: Diabetic microangiopathy. Adv Ophthalmol 1958;8:1-84.

2 Cunha-Vaz JG: Pathophysiology of diabetic retinopathy. Br J Ophthalmol 1978;62:351355.

3 Engerman RL, Kern TS: Experimental galactosemia produces diabetic-like retinopathy. Diabetes 1984;33:97-100.

4 Nunes S, Ribeiro L, Lobo C, Cunha-Vaz J: Three different phenotypes of mild nonproliferative diabetic retinopathy with different risks for development of clinically significant macular edema. Invest Ophthalmol Vis Sci 2013;54:4595-4604.

5 Lachin I, Genuth S, Nathan D, Zinman B, Rutledge B: Effect of glycemic exposure on the risk of microvascular complications in the diabetes control and complications trial - revisited. Diabetes 2008;57:995-1001.

6 Cunha-Vaz JG: The blood-ocular barriers. Surv Ophthalmol 1979;23:279-296.

7 Cunha-Vaz JG, Faria de Abreu JR, Campos AJ, Figo GM: Early breakdown of the blood- retina barrier in diabetes. Br J Ophthalmol 1975;59:649-656.

8 Bearse MA, Adams AJ, Han Y, Schneck ME, $\mathrm{Ng}$ J, Bronson-Castain K, Barez S: A multifocal electroretinogram model predicting the development of diabetic retinopathy. Prog Retin Eye Res 2006;25:425-448.

9 Antonetti DA, Klein R, Gardner TW: Diabetic retinopathy. N Engl J Med 2012;366:12271239.

10 Joussen AM, Poulaki V, Le ML, Koizumi K, Esser C, Janicki H, Schraermeyer U, Kociok N, Fauser S, Kirchhof B, Kern TS, Adamis AP: A central role for inflammation in the pathogenesis of diabetic retinopathy. FASEB J 2004; 18:1450-1452.

11 Kaur C, Foulds WS, Ling EA: Blood-retina barrier in hypoxic ischaemic conditions: basic concepts, clinical features and management. Prog Retin Eye Res 2008;27:622647.

12 Reis A, Mateus C, Melo P, Figueira J, CunhaVaz J, Castelo-Branco M: Neuroretinal dys- function with intact blood-retinal barrier and absent vasculopathy in type 1 diabetes. Diabetes 2014;63:3926-3937.

13 Simões MS, Lobo C, Egas C, Nunes S, Carmona S, Costa M, Duarte T, Ribeiro L, Faro C, Cunha-Vaz J: Genetic variants in ICAM1, PPARGC1A and MTHFR are potentially associated with different phenotypes of diabetic retinopathy. Ophthalmologica 2014; 232:156-162.

14 Arar NH, Freedman BI, Adler SG, Iyengar SK, Chew EY, Davis MD, Satko SG, Bowden DW, Duggirala R, Elston RC, Guo X, Hanson RL, Igo RP Jr, Ipp E, Kimmel PL, Knowler WC, Molineros J, Nelson RG, Pahl MV, Quade SR, Rasooly RS, Rotter JI, Saad MF, Scavini M, Schelling JR, Sedor JR, Shah VO, Zager PG, Abboud HE; Family Investigation of Nephropathy and Diabetes Research Group: Heritability of the severity of diabetic retinopathy: the FIND-Eye study. Invest Ophthalmol Vis Sci 2008;49:38393845. 